\title{
Recent Empirical Evidence on Discrimination by Regulated Firms
}

\author{
DAVID REIFFEN
}

U.S. Department of the Treasury

and

MICHAEL R WARD

University of Illinois

\begin{abstract}
Well-established economic principles show that regulated monopolies may have an incentive to act discriminatorily against rivals of their unregulated affiliates. This paper discusses some recent empirical evidence regarding discrimination in telecommunications. Specifically, it surveys anecdotal and systematic evidence that LECs discriminate against unaffiliated providers of mobile telephony. Evidence regarding discrimination by LECs against rival local phone companies is also discussed. At the same time, the evidence suggests that allowing LECs to enter cellular telephony may result in higher-quality or lower-cost cellular phone provision. These findings provide evidence that discrimination is a real phenomenon, and that there is a policy trade-off between preventing discrimination (by mandating separation) and realizing economies of scope.
\end{abstract}

\section{Introduction}

The recent battle over the Tauzin-Dingell bill is the latest chapter in the on-going saga of U.S. local telephone service regulation. The Tauzin-Dingell bill would, among other things, relax the regulations governing when the regional Bell Operating Companies (BOCs) would be allowed to offer broadband services in areas in which they also provide local telephone service. A key aspect of this debate is the potential for BOCs to discriminate against rival providers of broadband services. Under fairly general conditions, a regulated firm (such as a local telephone company) entering an unregulated related business (such as broadband) that uses as an input a good produced by the regulated firm (such as end-user access) has an incentive to alter the terms with which it deals with other sellers of the unregulated product. Specifically, well-established economic principles indicate that a regulated monopolist with an affiliate in an unregulated business may have an incentive to deny the affiliate's competitors access to an "essential" input, or more

\footnotetext{
* Contact author. Mailing address: Room 4409 MT, 1500 Pennsylvania Ave, NW, Washington, DC 20220, U.S. E-mail address: David.Reiffen@do.treas.gov The views expressed here reflect the views of the authors alone, and do not necessarily reflect the views of any organization. In particular, the views expressed here do not necessarily reflect those of the U.S. Treasury Department.
} 
generally, degrade the quality of the input supplied to the competitors. This incentive can arise because an integrated firm can mitigate the effects of price regulation on the input by shifting some of the potential input monopoly profits to the final product. Denying competitors, especially those producing close substitutes to the unregulated affiliate, access to the input reduces competition in the final good market, and as a result the integrated firm's profits on the final good can approach the potential input monopoly profits.

The premise that a regulated monopolist that is integrated into an unregulated business might discriminate against its rivals has been incorporated into U.S. telecommunications policy for the past 20 years. ${ }^{1}$ Perhaps the best example of how this principle has been incorporated into current U.S. policy is Section 271 of the 1996 Telecommunications Act. By virtue of the 1984 Modified Final Judgement in U.S. vs. $A T \& T$, the BOCs were prohibited from providing long-distance telephone service. Section 271 relaxes this prohibition, by permitting BOCs to enter long-distance telephony under certain conditions. Of particular interest is the provision that requires any $\mathrm{BOC}$ wishing to offer long-distance service originating in a state in which it provides local service to demonstrate that certain conditions exist that indicate the presence of sufficient competition for its local service. Presumably, one rationale for this policy is that absent sufficient local competition, once a BOC entered long distance, it would have an incentive to use its position in local telephone service to disadvantage other providers of longdistance telephone service. ${ }^{2}$ Local competition both gives rival long-distance companies an alternative means of access to local customers, thereby diminishing the BOC's ability to disadvantage downstream rivals, and likely reduces the BOC's profit-maximizing unregulated price, which also reduces the incentive to discriminate.

Whether a prohibition on integration by a regulated firm into an industry that uses an input provided by that firm is justified depends not only on the existence of a potential for discrimination, but also on whether there are offsetting efficiency losses from that prohibition. In some industries, the regulated firm may be the lowest-cost provider of some unregulated service. For example, in telephony, some have argued (e.g., Alchian, 1995) that there are economies of scope between local telephone service and long-distance telephone service, so that a BOC-affiliated long-distance company could profitably offer lower long-distance prices than existing long-distance companies. These efficiencies could result from better use of switching facilities, or something as mundane as reducing the cost of billing. In addition, some consumers may prefer the "one stop shopping" offered by integrated companies.

It follows that appropriate policy toward regulated firms that wish to integrate depends on a determination of the relative costs due to discrimination versus the cost of missing out on potential efficiencies. Hence, theory alone does not provide a clear guide to policy; instead, some estimates of the empirical magnitude of the effect of discrimination and the size of the efficiencies gains are required. The goal of this paper is to describe some of the recent systematic and other empirical evidence that document these effects. This evidence suggests that within the current regulatory framework, firms do appear to use their monopoly position in certain activities (e.g., the local loop) to reduce the effectiveness

\footnotetext{
${ }^{1}$ This premise has also been reflected in the regulation of electricity distribution in the U.K. and California.

${ }^{2}$ This interpretation of Section 271 can be found in Schwartz (2000). He also provides several additional justifications for this provision.
} 
of competitors. At the same time, there is evidence of off-setting efficiencies from integration.

Section 2 of this paper details theoretical results regarding when discrimination will be profitable. We then survey some evidence regarding discrimination in telecommunications and electricity transmission in section 3. Section 4 discusses why cellular telephony provides a useful experiment for examining discrimination, followed by an analysis of some evidence of discrimination in that industry. Finally, section 5 discusses the implication of this evidence for future policy.

\section{Regulated firms and the incentive to discriminate}

There is a considerable literature that addresses the question of whether a firm that sells an input whose price is regulated might discriminate against users of that input who compete with its unregulated affiliate. The basic rationale for why discrimination may be profitable dates back at least to Bowman (1957). Bowman's insight is that a firm that has a product whose price is regulated may attempt to, in effect, evade that regulation by tying the purchase of the price-controlled good to some other product. The firm will then be able to capture some of the profit lost due to price regulation through increased sales of the unregulated, tied product.

The same logic explains why a regulated firm may wish to discriminate or "sabotage" (i.e., lower the quality of) the input sold to competitors of its downstream (i.e, input-using) affiliate; sabotage increases the sales of its unregulated product (Ordover, Sykes and Willig, 1985; Brennan, 1987). ${ }^{3}$ More recent literature has explored the issue of when the incentive to sabotage does, or does not exist. The basic logic is that sabotage involves the sacrifice of upstream profits (the margin on the input sales lost due to sabotage) in exchange for higher downstream profits. Hence, factors that increase the upstream profit from sales to the rival make sabotage less profitable, and factors associated with a greater downstream gain from sabotage make it more profitable. As such, at least four factors have been show to be relevant. This literature shows that when the regulated price is below the profit-maximizing price, the incentive to sabotage the input sold to rivals is increasing in:

- The difference between the regulated firm's regulated price and the profitmaximizing price;

- The degree of substitutability of the affiliate's product with those of its rivals;

- The relative efficiency of the unregulated affiliate compared to that of its rivals, and decreasing in:

- The cost of sabotaging rivals' products.

\footnotetext{
${ }^{3}$ For this reason, the second market need not be unregulated for discrimination to occur. What is required is that marginal revenue in the second market exceeds the firm's marginal cost in that market, so that the lost sales would have been profitable.
} 
The logic of these results relates directly to the size of the upstream margin on sales of the input to the rival versus the downstream gain from discriminating against the rival. Hence, the more substitutable are the downstream products, the more a given reduction in the rival's sales will lead to higher sales by the affiliate, and a greater incentive to discriminate (see e.g., Reiffen, 1998). ${ }^{4}$ When the products are perfect substitutes and the affiliate has the same costs as its rival, then discrimination will be profitable, since on the margin, the change in the integrated firm's profits will be equal to the difference between (pre-sabotage) price and cost on the rivals' last unit. The higher the affiliate's costs are relative to its rival, the lower the effect of any given increase in sales on the integrated firm's profits, thus weakening the incentive to discriminate. However, even when the affiliate has higher costs than its rival, discrimination will be profitable when products are homogeneous unless the cost disadvantage is large (Mandy, 2000; Bergman, 2000) or the regulator can effectively limit the extent of discrimination (Weisman and Kang, 2001). ${ }^{5}$

Similarly, discrimination is more attractive when its effect on upstream profits is small. Therefore, discrimination is more likely to be profitable when the regulated price is well below the profit-maximizing price, so that the upstream margin on the lost sales is small, and when the sabotaged input is cheaper to produce than the non-sabotaged version (Reiffen, 1998).

This literature suggests that whether discrimination should be a concern in a specific industry depends on empirical magnitudes. It follows that in order to determine appropriate policy towards a regulated firm seeking to enter a related, unregulated business, policy makers require estimates of these magnitudes. Of course, good estimates will be unavailable if the firm has been prohibited from the unregulated business (e.g., BOCs and long-distance telephony). In addition, having estimates of some of these magnitudes may yield ambiguous implications. For example, knowing that the regulated firm will be a lowcost provider of the unregulated service means that it will have a greater incentive to discriminate, but also that there may large gains in productive efficiency by allowing it to enter that line of business (Weisman and Kang, 2001). This literature suggests another difficulty for regulators; the direct effect of setting the upstream price close to marginal cost is a benefit for both the downstream firms that use the product as an input, and social welfare. However, an indirect effect is an increase in the upstream firm's incentive to discriminate, mitigating or eliminating the benefit. ${ }^{6}$

The next section presents some evidence that discrimination is present is several regulated industries. This provides some basis for determining when the conditions for sabotage to be profitable are likely to be met in other industries.

\footnotetext{
${ }^{4}$ Mandy and Sappington (2001) show this is true for Bertrand (Nash equilibrium in price) competition, but is not necessarily uniformly true for Cournot (Nash in quantity) competition. However, even in the Cournot case, the incentive to discriminate disappears when the products are weak substitutes, and is always present when the products are homogeneous, and the downstream firms have identical costs (Economides, 1998). ${ }^{5}$ Another interpretation of the affiliate having higher costs is if it has finite capacity. Sibley and Weisman (1998) show that for sufficiently small capacity (relative to market size), discrimination will not be profitable, and in fact the integrated firm would like to lower the rival's costs.

${ }^{6}$ One can view the literature on the Efficient Component Pricing Rule (see, e.g., Baumol, Ordover and Willig, 1997), as relating to the trade-off between monopoly pricing of the input and sabotage.
} 


\section{Evidence of discriminatory behavior}

The 1984 breakup of AT\&T into separate long-distance and local telephone companies was predicated in part on a history of discriminatory action by AT\&T against its rivals in longdistance telephony and equipment manufacture. With respect to long-distance, AT\&T had a monopoly over a service that was a necessary input to any firm selling the product. $^{7}$ Specifically, in many geographic areas, AT\&T owned the telephone lines between most individual end users and the switch (which it also owned) that connected those lines to the network of telephones (sometimes called the local loop).

Figure 1 depicts a stylized representation of a local telephone network. Most end users are connected by small-capacity lines to "end offices" which are small, neighborhood gathering points. In turn, end offices are connected by large-capacity lines to a "tandem" switch. A call between users connected to different end offices will be "switched" at least three times; once at the initiating caller's end office, once at the tandem switch, and once at the recipient's end office. In addition to serving as a hub of the local system, a tandem switch also provides the connection between the local network and long-distance lines.

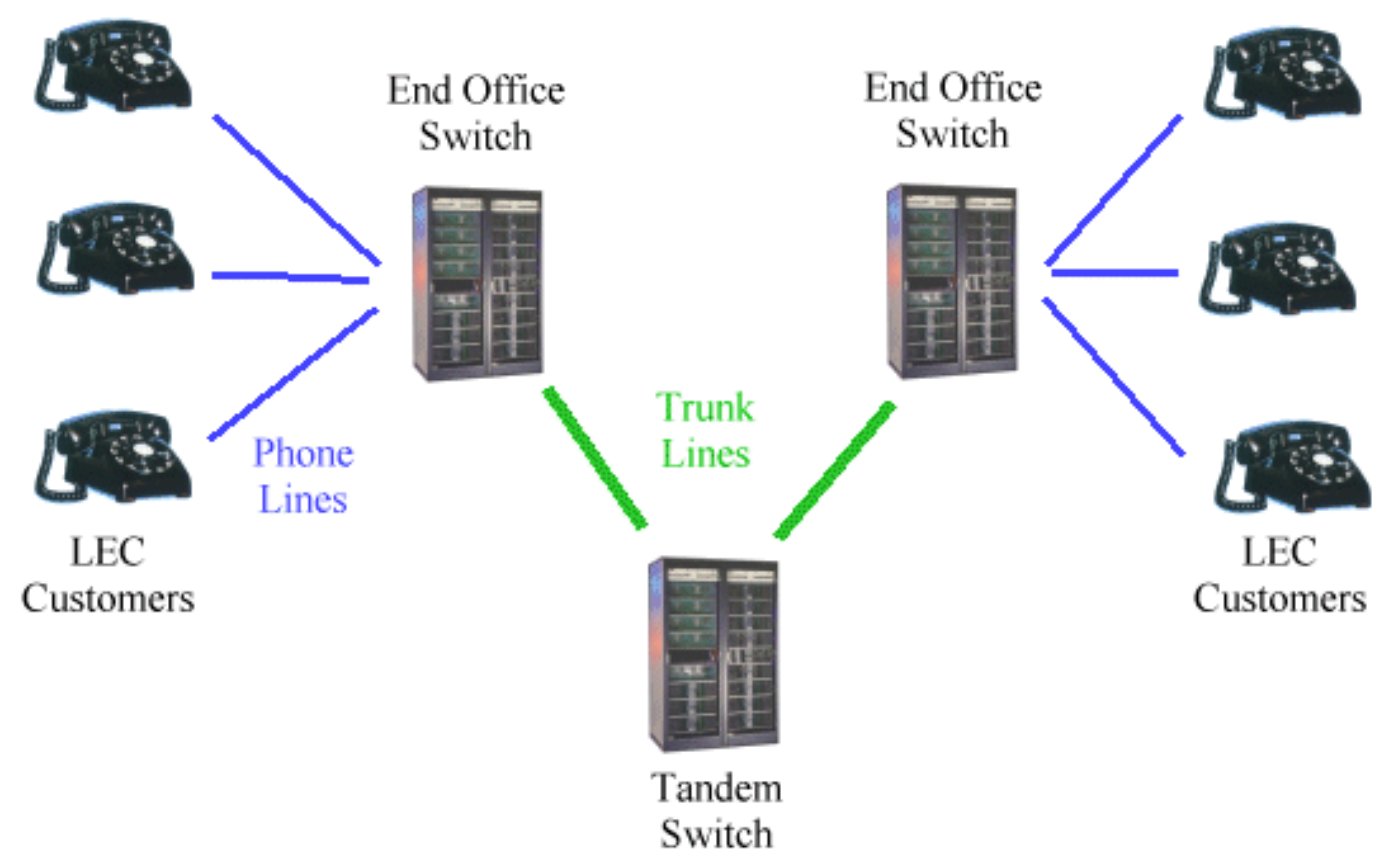

Figure 1: Typical Local Telephone Network Configuration

In the period preceding US v. AT\&T, rivals like MCI had constructed means for transmitting intercity calls. What they lacked was the ability to route a call between their point of presence in a city and most local end-users. ${ }^{8}$ Connecting most customers required

\footnotetext{
${ }^{7}$ The analysis is similar for equipment, except that for equipment, AT\&T was the primary purchaser, rather than the monopoly supplier of an input.

${ }^{8}$ During this period, MCI primarily focused on consumers with a sufficient volume of calls to justify the cost of constructing a line from the customer to MCI's point of presence.
} 
either access to the AT\&T network (through the tandem switch), or constructing a parallel network. For all but the largest customers, it was considered prohibitively costly for a rival to replicate AT\&T's local network, so that as a practical matter, any rival that sought to provide long-distance telephony service to these customers would need access to the AT\&T local network.

The evidence assembled in $U S v . A T \& T$ suggests that the conditions under which discrimination would be profitable were met (e.g., other long-distance services were sufficiently close substitutes for AT\&T's). That is, AT\&T apparently attempted to prevent rivals such as MCI from competing in long-distance telephony or make their service less attractive. For example, for a substantial portion of time, AT\&T did not allow end users to have direct access to rival long-distance companies' networks. Instead, to make a longdistance using a non-AT\&T carrier, a customer would have to first dial that carrier's local telephone number to obtain a connection, then have to dial his or her account number, and finally the destination parties' telephone number (see Noll and Owen, 1989). Not only was this less convenient than using AT\&T for long distance, but the sound quality of the call was lower.

This kind of discriminatory behavior has not been confined to telephony. A leading U.S. example outside of telephony are the actions of Otter Tail Power with respect to its rivals. ${ }^{9}$ Otter Tail was a regulated utility that owned transmission lines capable of bringing electric power to certain municipalities in the northern plains. For most of these municipalities, the electricity was also generated by Otter Tail. During the 1960s, several of these municipalities decided to instead purchase power from some other source, and use Otter Tail's facilities to transmit this power. In at least four such instances, Otter Tail refused to provide unbundled transmission services. That is, like the integrated AT\&T in the 1970s, Otter Tail denied access to a necessary input (here, transmission lines) to rivals (here, rival generators of electricity).

Introducing local telephone competition raises issues that are similar to those raised in introducing long-distance competition. Sections 251 and 253 of the 1996 Telecommunications Act envisions a range of means by which local competition can be introduced. All of these require the incumbent LEC to provide some inputs to the entrant. The most self-reliant means of entry is for an entrant to build an entire parallel network, including lines from end offices to individual end users, as well as the trunk lines and tandem switch(es) to connect its end offices. Even in this case, some of the incumbent's switching facilities are required to complete a call between subscribers to the two systems. Some of the other means of entry require greater degrees of cooperation by the incumbent. For example, entry can take the form of a firm that does not build any facilities, but simply resells the LEC's existing service, so that the primary value-added of the entrant is in a consumer-interface service such as billing. In that case, the incumbent supplies all of the physical assets required to complete a call. An intermediate type of entry is to install one's own facilities for a subset of the required functions and to lease the remaining components, called "Unbundled Network Elements," from the LEC.

Hence, unless the local entrant constructs a complete parallel network, some aspects of local telephony will remain monopolized and regulated. For this reason, the same analysis of the incentives of a regulated firm (here, the firm which owns the wire between end offices and end users) that competes in a vertically-related market (other parts of local

\footnotetext{
${ }^{9}$ For further details, see Kleit and Michaels (1994).
} 
telephony) will be relevant. If the entrant's local switching service is as close a substitute for the incumbent's service as entrant long-distance companies were for AT\&T, then one might expect that a firm that has a monopoly on the last mile and provides local switching would discriminate against other firms providing local switching.

As discussed in the Introduction, the Act mandates that incumbent LECs allow such access on a non-discriminatory basis. As the history of AT\&T and other regulated firms indicates, there is reason to doubt whether this aspect of the Act is adhered to. In fact, a recent study by Mini (2001), provides systematic evidence that discrimination by regulated local telephone companies against rivals is still a relevant concern. ${ }^{10}$ Mini takes advantage of the discrepancy between the regulatory treatment of the BOCs and GTE to examine the extent to which they provide access to monopolized assets. Specifically, GTE differs from the BOCs in two important ways. First, unlike the BOCs, it was never prohibited from providing long-distance service. ${ }^{11}$ Second and relatedly, while all local telephone companies are obligated to make their facilities available to local competitors at cost-based prices, the BOCs have an additional incentive to meet this obligation. As claimed above, if a BOC can demonstrate the existence of certain indicators consistent with competition in one of its local markets, the company is permitted to provide long-distance service between that market and other areas.

Mini hypothesizes that because the BOCs have greater incentive to cooperate with rival local telephone customers than GTE, the observed pattern of negotiation over access between BOCs and their rivals will be more favorable to the rivals than will the negotiations between GTE and its rivals. To test this hypothesis, Mini examines the experience of AT\&T in negotiating with GTE and the BOCs in the post-1996 period.

AT\&T was one of the firms that sought to enter the local telephone business and requested access to LEC local loops. In 22 states, AT\&T had to negotiate with both GTE and a BOC (in different areas within the state) to gain such access. Mini takes advantage of this natural experiment in how differently-regulated firms treat the same entrant by comparing the contractual terms and the length of the negotiation process across LECs in each state. Mini finds a consistent pattern: Contracts between AT\&T and the relevant BOC were negotiated more quickly (permitting earlier AT\&T entry) than contracts between AT\&T and GTE, and negotiations with a BOC resulted in more favorable terms to AT\&T. For example, in 12 of the 14 states with data, the share of local loops leased by AT\&T is larger in the BOC-controlled area than in the GTE-controlled area of the state. Hence, consistent with the premise that incumbent LECs discriminate against competing local service providers, the degree of LEC cooperation with local entrants varies in a predictable way with its incentive to discriminate.

\section{$4 \quad$ Evidence from cellular telephone markets}

The systematic evidence provided by Mini, as well as the history of AT\&T and other regulated firms, points to the empirical relevance of the discrimination hypothesis. What is

\footnotetext{
${ }^{10}$ Recent work by Crandall (2001) suggests that competitive local phone companies are at least as good a substitute for LECs as MCI was for AT\&T.

${ }^{11}$ An earlier study by McChesney (1995) also takes advantage of the disparate regulatory treatment of the BOCs and GTE to test for discrimination. McChesney examined relatively aggregate data and found no evidence of discrimination. Mini's more disaggregate data permits a cleaner test of the hypothesis.
} 
less clear is the evidence regarding efficiencies. In this section, we discuss some recent evidence regarding discrimination and efficiencies in the wireless telephone industry.

In many ways, the relationship between wireless telephone providers and LECs is quite similar to the relationship between long-distance telephone companies and LECs. In both cases, the seller of the other product requires interconnection so as to complete calls between customers of both networks. A brief description of how cellular telephone service, the first widely-available wireless technology, was provided will help make this clear. ${ }^{12}$

Cellular telephone companies provide wireless service by using FM frequencies to connect mobile telephones to a cellular antenna. Each geographic area that has cellular service is divided into honeycombs of "cells" - small areas associated with each antenna. The benefit of having a large number of antennae is that the distance between the telephone and the antenna will be relatively small, allowing the transmission to be made at low power. This permits the same frequency to be used simultaneously in multiple cells within a geographic area (although not in adjacent cells).

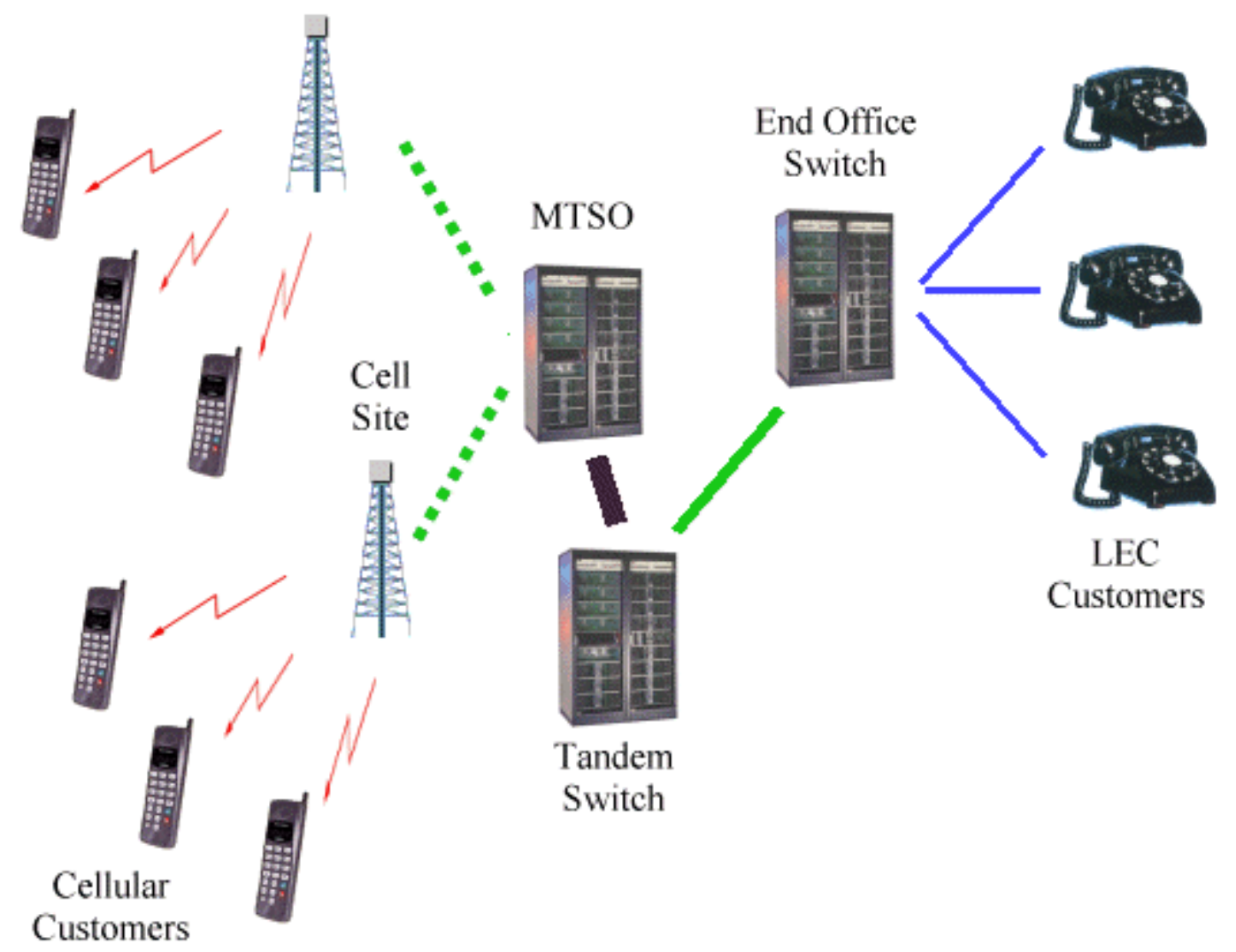

Figure 2: Typical Cellular Telephone Network Configuration

\footnotetext{
${ }^{12}$ The essential element of the relationship between cellular providers and LECs is also present in the relationship between PCS (the other major wireless technology) providers and LECs. In both cases, the LEC provides the connection between facilities of the wireless companies, and between these facilities and the local loop.
} 
The stylized depiction of cellular networks in Figure 2 helps illustrate the parallel between cellular and long distance services. As shown in Figure 2, once the signal is transmitted to the antenna, it must be transmitted to the cellular company's Mobile Telephone Switching Office (MTSO) via a landline or microwave link. If there is a landline connection, it is typically provided by a LEC. In addition, for calls to a local landline subscriber (which represent the majority of calls), the signal is then linked through a LEC's tandem switch to its landline network.

Hence, as is the case for long-distance service, LECs provide a necessary input into a cellular company's service. In addition, as is the case for interconnection rates charged to long-distance companies, LECs are regulated in regard to the pricing of interconnection with cellular companies. However, there is one important difference between the cellular and long-distance markets. In contrast to long-distance, the BOCs are allowed to own one of the two cellular companies in each geographic area. To the extent discrimination is feasible, we would expect the regulated LECs would treat their affiliated cellular providers differently than their affiliate's rival.

The U.S. Federal Communications Commission (FCC) has recognized the potential for a regulated LEC to use its control over the landline network to disadvantage rivals of its affiliate. "Discrimination results when a LEC uses its control over bottleneck facilities to discriminate against competitors to the LEC's CMRS (Commercial Mobile Radio Service) subsidiary by providing inferior interconnection services. This discrimination can take many forms, such as providing inferior quality interconnection, providing fewer lines (thus reducing the capacity of the competing system to complete calls), delaying fulfillment of request for interconnection services, . . and providing inferior quality repair services." 13

Indeed, given these features of the cellular industry, it is not surprising that there is evidence of discriminatory behavior by local telephone companies. Specifically, during Bell Atlantic's 271 hearing regarding service in New York state, complaints were voiced about Bell Atlantic's provision of interconnection services to rival wireless carriers. Omnipoint, a provider of PCS service, noted that it relies exclusively on Bell Atlantic to provide the connection between its antennae and nearest switch, and that Bell Atlantic's record of providing these connections has been "abysmal." For example, it noted that "Bell Atlantic missed between $34 \%$ and $65 \%$ of 'Firm Commitment Order' dates" (installation dates agreed to in advance) for connecting new antennae in the New York Metropolitan area. ${ }^{14}$ In its Comment, Omnipoint also claimed that Bell Atlantic discriminatorily provided lower-quality interconnection than it provided Bell Atlantic's own customers. ${ }^{15}$

These complaints have focused on the provision of interconnection to new antennae. It is plausible that discrimination against rival wireless companies could take this form, both because such discrimination is difficult for regulators to detect, and because it is potentially significant to wireless carriers. This second point follows directly from the fact that the number and location of antennae are a key aspect of a system's quality. This is because each antenna has finite capacity and transmissions have limited range, so that as demand grows and changes within a market, wireless companies need to install new

\footnotetext{
${ }^{13}$ Competitive Safeguards Order, 122 FCC Rcd at 15689.

${ }^{14}$ Omnipoint Comment at $7 / 8$.

${ }^{15}$ ibid. at 11-13. Several firms seeking to provide competitive local service in New York state offered similar complaints about Bell Atlantic's service during the 271 Hearing. During these Hearings, two other telephone companies, Allegiance and Teligent, complained that they experienced excessive delays in obtaining new interconnection.
} 
antennae to maintain quality. For example, if the number of calls to a specific antenna increase, the quality of the connection, or indeed the ability to provide any connection may deteriorate. $^{16}$

These claims that LECs differentially favor their affiliated wireless carriers when integrating new antennae provide some evidence that discrimination exists in these markets. As emphasized above, evidence that discrimination exists in cellular markets is not sufficient to allow one to conclude that integration should be prohibited; some estimate of the potential for efficiencies must also enter the decision-making. A recent paper by Reiffen, Schumann, and Ward (2000) takes advantage of some features of cellular markets to examine the extent of discrimination and also whether efficiencies are sufficient to offset the losses due to discrimination. The feature of U.S. cellular markets (as geographically defined by the FCC licenses) that permits this test is that the incentive and ability to discriminate differs across geographic areas. Thus, like the Mini study, Reiffen et al. examine whether the extent of discrimination varies with the incentive and ability to discriminate, as theory would predict.

There are differences between markets in the leading LEC's ability to discriminate because cellular markets differ with respect to the number of LECs serving the area. For example, in some U.S. cellular markets (such as New York or Washington), a single LEC provides local telephone service throughout the market. In other markets, such as Los Angeles or Cincinnati, there are multiple (non-competing) LECs providing service in different parts of the same cellular market. ${ }^{17}$ In their sample, markets with a single LEC were the exception, accounting for less than $5 \%$ of cellular markets. On average the largest LEC owned about $75 \%$ of the end offices in each market.

These differences in landline ownership across markets are also reflected in the ownership of the equity in the affiliated cellular company. In each metropolitan area in the U.S., two cellular licenses were awarded by the FCC, one of which (the "B" license) was reserved for a LEC in that area. In areas with multiple LECs, this license was to be awarded to one of the local LECs, chosen through comparative hearings. However, the FCC encouraged the LECs in each area to reach a settlement regarding this award. Consequently, in most markets with multiple LECs, the B side cellular company is jointly owned by multiple local LECs. Thus, the concentration of ownership of B side cellular companies varies across markets.

What this means is that both the incentive and the ability of LECs to discriminate against their cellular affiliates' rivals will differ across markets: Other things equal, markets in which ownership of the affiliated LEC is concentrated (e.g., held by one firm) will be characterized by more discrimination than markets in which ownership is dispersed. The reason is that discrimination reduces the profits of a LEC that discriminates (because it will carry less cellular traffic, and interconnect fewer antennae), while it simultaneously

\footnotetext{
${ }^{16}$ Indeed, as the popularity of cellular telephone grew, the number of cell sites also grew dramatically in the 1990s. Using CTIA data, we calculate that the number of sites in the U.S. grew an average of $35 \%$ per year during the decade. In addition to market-wide growth in cellular use, demand for new cell sites can arise in particular areas of a market. For example, there may be small, localized parts of a market (e.g., freeway exits) where an unusually large number of calls originate. Such "hot spots" require additional cells in a specific locality.

${ }^{17}$ That is, during the period studied (1995), each LEC faced virtually no competition. Cellular markets differed as to whether the local monopolist was the same throughout the market, or whether two or more monopolists provided service in different parts of the market.
} 
increases its cellular affiliate's profits. A LEC's view of the trade-off between LEC profits and affiliate's profits changes with its ownership interest in the affiliate. For example, a LEC that owned $100 \%$ of the affiliate's equity will have more incentive to discriminate than if it owned $50 \%$ of the cellular company's equity, because it would receive more of the effect of higher cellular profits for any given reduction in its own profits. Reiffen et al. show that because some of the benefit of higher cellular company profits redounds to other owners, aggregate discrimination will be (for example) lower in a market with two LECs, each of whom own $50 \%$ of the cellular company's equity, than one in which one firm owns $100 \%$ of its equity. At the same time, the ability of the largest LECs (who own the greatest share of the cellular company's equity) to discriminate will be proportional to their ownership of switches and other assets used to provide interconnection, and hence lower concentration of asset ownership will be associated with less discrimination.

Another way of thinking about this is that differences in the concentration of assets used to interconnect, and in the ownership of the cellular company's equity are analogous to differences in the extent of vertical integration. The theory implies that the greater the degree of vertical integration, the more discrimination will occur. At the same time, the extent of efficiencies (if they do exist) should also vary with the extent of integration. Recall from Figure 2 that new antennae require a connection to an existing end office. In most circumstances, the easiest way to accomplish this is to add additional capacity to existing facilities (e.g., new lines to the LEC's existing right-of-way). This requires cooperation between the LEC and the cellular company.

It is plausible that cooperation between a cellular company and a LEC is facilitated by the LEC's ownership of the cellular company. That is, while in principle, separate companies could reach the same agreement via contract, integration may entail lower transactions cost. One kind of transactions cost savings that may be relevant here stems from the fact that some of the investments made by the cellular company are highly specific to its relationship with the LEC (e.g., virtually worthless if the LEC discontinues providing services). Hence, prior to making investments, cellular companies would like some assurance that LECs will provide the requisite services, and not try to appropriate the value of those investments (as in Klein, Crawford, \& Alchian, 1978). Because LECs with greater equity ownership in the cellular companies have more incentive to maximize joint profits (i.e., have less incentive to appropriate these investments), it follows that cellular companies in markets with greater concentrated of equity ownership will likewise make production decisions that come closer to maximizing joint profits. For example, a cellular company that is $100 \%$ owned by a LEC will be more likely to invest in new transmission towers specific to that LEC, because the LEC's incentives are better aligned with its own, and hence it knows the LEC is more likely to promptly and efficiently provide connections incorporating the new towers into the cellular network. ${ }^{18}$

These considerations suggest that under either hypothesis, cross-sectional differences in equity ownership should lead to predictable differences across cellular markets. If the primary effect of integration between LECs and cellular companies is to

\footnotetext{
${ }^{18}$ Another means by which integration could increase output is through the use of a common brand name. Often, a cellular affiliate uses the brand name of the LEC with the largest equity interest in it (e.g., Verizon Wireless). If consumers prefer a cellular company with a recognizable name, output would be higher in markets in which the common brand name is familiar to more consumers (i.e., where the LEC has a large share of end offices). The use of brand names in this way is a kind of scope economy (as in Wernerfelt, 1988) and constitutes an efficiency, albeit of a different kind than discussed above.
} 
induce greater discrimination, then one would expect that rival cellular companies would have higher costs/lower quality in markets characterized by greater integration. This in turn would imply a negative relationship between measures of cellular use within markets and the concentration of LEC ownership of the cellular companies' equity and of physical assets. In contrast, if the primary effect of greater integration was to allow for scope economies, then one would expect higher affiliate quality in markets with greater concentration of LEC ownership, and consequently a positive relationship between cellular use and these concentration measures.

Of course, these two hypotheses are not mutually exclusive; greater integration could lead to both increased discrimination against rivals and higher quality/lower cost for the affiliate. What is relevant is the net effect of greater integration on consumers. To determine the net effect, Reiffen et al. examine a variety of measures of quality and cellular use to estimate the impact of differences in ownership concentration. Their data pre-date the introduction of PCS wireless service, so that the results they obtain regarding the effect on cellular use represent the effect on the use of all wireless telephony extant at that time. They find that the greater the extent to which end offices are owned by a single LEC, rather than dispersed across LECs, the higher will be average quality and greater the use of cellular telephones. In contrast, higher concentration of tandem switch ownership is associated with lower quality for its rival and lower cellular use. These effects are roughly offsetting in that (for example) comparing a market with two LECs, each of whom own half the end offices and half the tandems in the market to a market in which one firm owns $100 \%$ of both, the net effect on cellular use would be small. The conclusions are similar regardless of whether they examine cellular use (as an indirect measure of quality and price), or a more direct (albeit subjective) measure of quality such as consumers' satisfaction, or a direct measure of quality such as antennae per capita.

In addition to being robust to alternative measures of cellular quality, their results are both economically meaningful and statistically significant. For example, they find that a change in end-office ownership from two firms with half of the end offices each to one firm with all of the end offices would cause an increase in subscribership of slightly more than $5 \%$. At the same time, they find that a similar increase in concentration of tandem ownership would decrease subscribership by a slightly less than $5 \%$.

The result that higher end-office concentration has the opposite effect as higher tandem concentration is somewhat surprising. Reiffen et al. offer the following explanation for their findings. The connection to a new cell site requires connection to the end office, and between the end office and the MTSO. The largest LEC in each area is likely to supply this latter connection to every new cell site to which it supplies the first, and some additional connections as well (i.e., connecting the lines from the end offices of smaller LECs that do not own tandem switches and trunk lines). Hence, the larger LECs (who are most likely to want to discriminate) can discriminate on either of these connections for new sites for which it owns the relevant end office, but only on the second connection for the sites for which a small LEC owns the end office. Because tandem switch ownership is more concentrated than end office ownership, measures of tandem switch ownership provide a good measure of the number of new sites that the large LEC can discriminate against. For example, a LEC will have roughly the same ability to discriminate in a market in which it owns all the tandems and $90 \%$ of the end offices as one in which it owns all of both. While owning the additional $10 \%$ of end-offices does not materially increase the LEC's ability to discriminate, it may allow the affiliate to avoid 
some of the negotiation costs of dealing with a third party. Hence, holding tandem ownership constant at a high level, owning additional end offices tends to lead to efficiencies.

\section{Conclusion}

Well-established economic principles show that regulated monopolies may have an incentive to discriminate against rivals of their unregulated affiliates. The evidence demonstrating the existence of this behavior has moved beyond the anecdotal to the systematic. At least two recent studies find evidence that LECs do use their monopoly positions in particular telecommunications functions to disadvantage rival producers of other functions. In regard to local telephone service, the evidence suggests that forcing LECs to disintegrate certain services (e.g., marketing local telephone service) may well encourage competition in that service. Similarly, evidence from the cellular telephone industry suggests that independent mobile telephone service providers may experience improved service if LECs did not operate in the cellular telephone business.

At the same time, evidence from cellular markets suggests that there may be efficiency gains associated with vertical integration by regulated firms. Unfortunately, the literature on the gains from allowing regulated firms to enter unregulated business is less well-developed than the literature on discrimination. It seems likely, however, that as is the case in models of discrimination, the nature and magnitude of the efficiency gains will differ across regulated industries. If so, advances in understanding the sources of these efficiencies will have to proceed on an industry-by-industry basis. Despite the inherentlyincremental nature of the advances required, future studies at the industry level will be critical to understanding the nature of the trade-off involved in regulating the scope of activities of firms with some monopolized lines of business.

\section{$6 \quad$ References}

Alchian, A.A. (1995) "Vertical Integration and Regulation in the Telephone Industry" in Higgins and Rubin (eds.) Deregulating Telecommunications John Wiley and Sons (New York), pp. 44-9.

Armstrong, M., S. Cowan and J. Vickers (1994) Regulatory Reform: Economic Analysis and British Experience. MIT Press (London).

Baumol, W.J., J.A. Ordover, and R.D. Willig (1997) "Parity Pricing and Its Critics: A Necessary Condition for Efficiency in the Provision of Bottleneck Services to Competitors", Yale Journal on Regulation, 14: 145-63.

Bergman, M.A. (2000) "A Note on N. Economides: The incentive for Non-price Discrimination by an Input Monopolist", International Journal of Industrial Organization 18: 985-8. 
Bowman, W. (1957), "Tying Arguments and the Leveraging Problem", Yale Law Journal, 67: 19-36.

Brennan, T. (1987) "Regulated Firms in Unregulated Markets: Understanding the Divestiture in 'U.S. v. AT\&T'”, Antitrust Bulletin, 32: 61-87.

Crandall, R.W. (2001) "An Assessment of the Competitive Local Exchange Carriers Five Years After the Passage of the Telecommunications Act", working paper at http://www.usta.org/crandall_media_kit.html

Economides, N. (1998) "The incentive for Non-price Discrimination by an Input Monopolist", International Journal of Industrial Organization 16: 271-84.

Klein, B., R. Crawford and A. Alchian (1978) "Vertical Integration, Appropriable Rents, and the Competitive Contracting Process", Journal of Law and Economics 21: 297-326.

Kleit, A.N. and R.J. Michaels (1994) "Antitrust, Rent-seeking, and Regulation: The Past and Future of Otter Tail”, Antitrust Bulletin, 39: 689-725.

Mandy, D.M. (2000) "Killing the Goose That May Have Laid the Golden Egg: Only the Data Know Whether Sabotage Pays", Journal of Regulatory Economics 17: 157-72.

Mandy, D.M. and D. Sappington (2001) "Incentive for Sabotage in Vertically-Related Industries", Working paper at $<$ http://bear.cba.ufl.edu/sappington/pprs.html $>$.

McChesney, F. (1995) "Empirical Tests of the Cross-Subsidy and Discriminatory-Access Hypotheses in Vertically Integrated Telephony", Managerial and Decision Economics 16: 493-505.

Mini, F. (2001) "The Role of Incentives for Opening Monopoly Markets: Comparing GTE and BOC Cooperation with Local Entrants", Journal of Industrial Economics, 43: 379-424.

Noll, R. and B. Owen (1989) "The Anticompetitive Uses of Regulation: United States v. $A T \& T$ ' in The Antitrust Revolution (White and Kwoka, eds), Scott, Foresman and Co.(Glenview, Il.).

Ordover, J.A., A.O. Sykes, and R.D. Willig (1985) "Nonprice Anticompetitive Behavior by Dominant Firms toward the Producers of Complementary Products" in Antitrust and Regulation: Essays in Memory of John J. McGowan, MIT Press, Cambridge, MA, pp. 115130.

Reiffen, D. (1998) “A Regulated Firm's Incentive to Discriminate: A Reevaluation and Extension of Weisman's Result”, Journal of Regulatory Economics, 14: 79-86.

Reiffen, D., L. Schumann and M.R. Ward (2000) "Discriminatory Dealing with Downstream Competitors: Evidence from the Cellular Industry", Journal of Industrial Economics, 48: 253-88. 
Schwartz, M. (2000) "The Economic Logic for Conditioning Bell Entry into Long Distance on the Prior Opening of Local Markets", Journal of Regulatory Economics, 18: 247-88.

Sibley, D., and D.L. Weisman (1998) "Raising Rivals' Costs: Entry of an Upstream Monopolist into Downstream Markets", Information Economics and Policy, 10: 551-70.

Weisman, D.L. and J. Kang (2001) "Incentives for Discrimination when Upstream Monopolists Participate in Downstream Markets", Journal of Regulatory Economics, 20: 125-39.

Wernerfelt, B. (1988) "Umbrella Branding as a Signal of New Product Quality: An Example of Signaling by Posting a Bond", Rand Journal of Economics, 19: 458-66. 